\title{
The origins of journalism education at UPNG
}

\section{By PETER HENSHALL}

JOURNALISM education and training was started at the University of PNG at the beginning of 1975, when the New Zealand Government agreed to fund a one-year Diploma in Journalism for an initial two-year period. before this, the few national journalists employed in Papua New Guinea had been trained in-house by the two principal employers of the time. - the Office of Information and the National Broadcasting Commission. Independence and the rapid expansion worldwide of the communications sector meant that PNG faced a serious shortfall in media personnel, in both quantity and quality.

A pilot project in 1974, in which 12 national journalists were sent to Wellington Polytechnic, New Zealand, to do a journalism course, had been a failure. It proved too difficult for the students to make the necessary adjustments to the very different culture and climate, and at the same time cope with the demands of a course designed for people for whom English is their first language.

The governments of New Zealand and PNG agreed to reverse the process and send instead an experienced journalism teacher to PNG. The decision was taken to base him at UPNG, as the only institution in the country capable of supplying all the necessary academic facilities to support such a program.

The New Zealand Government extended funding of this scheme by one year beyond the original agreement and then, in 1978, the PNG Government took over financial responsibility for it, through its budgetary grant to UPNG. In those first three years 44 journalists undertook the course, several of whom had been in the profession for some time with no formal training.

Betwen 1978 and 1981, the university received from the media in PNG the view that the program should be expanded. In particular, the National Broadcasting Commission wanted components on broadcast journalism. The students, too, wanted more university level education. It was agreed to expand the program, and overseas funding was sought. This 


\section{JOURNALISM EDUCATION AT UPNG From previous page} came to nothing, however, and in 1983 and 1984 UPNG undertook internal reorganisation to make it possible to employ a second lecturer in journalism, and advertised the position.

At the beginning of 1985, the two-year Diploma in Media Studies was offered for the first time, and the first students graduated at the end of 1986. The four-year Bachelor of Journalism degree program was offered for the first time in 1986, to students who had already successfully completed the university's general foundation year. The first students [graduated] with this qualification at the end of 1988 .

The late Peter Henshall wrote this commentary as part of a paper, 'Journalism Education and Training at the University of Papua New Guinea', published in Pacific Islands Communications Journal, 15:2, 1988, pp 32-39.

shade and the closed doors and the secrecy,' he said.

In May 1997, Sir Anthony appealed at a seminar organised by the Ombudsman Commission for the media to educate the people and encourage them to become 'a nation of whistleblowers' to curb the corruption that has become 'endemic'.

In the wake of the Sandline mercenary affair, these are all noble and popular sentiments echoed by many community leaders and leading politicians anxious to sign the national integrity pledge. But little thought is given to how the media actually fulfills this serious responsibility.

Both the national dailies and weeklies, and EM TV (in particular John Eggins with his documentary The Ultimate Test) have performed creditably with some robust journalism and excellent in-depth reports. Yet quality journalists don't just suddenly materialise. They are the product of sound training and a broad liberal education in their formative years, honed by experience in competitive and diverse media organisations.

The Papua New Guinea news media has been well-served by the education system - according to recent research some 68 per cent of PNG journalists have a university or tertiary qualification. ${ }^{1}$ This is far higher than Fiji (16 per cent, although this should climb rapidly with the new journalism school at the University of the South Pacific) and slightly higher than Queensland.

A generation of journalists have been educated since independence at the University of Papua New Guinea and more recently at the Divine Word University (formerly Institute). In this era of mass-oriented, depersonalised and conformist type of global journalism, there is a vital need for critical, thinking 